OPEN ACCESS

Edited by:

Iker Aranjuelo,

Superior Council of Scientific

Investigations, Spain

Reviewed by:

Sung Chul Lee,

Chung-Ang University, South Korea

Scott McAdam,

Purdue University, United States

${ }^{*}$ Correspondence:

Yang Gao

gaoyang@caas.cn

Aiwang Duan

duanaiwang@caas.cn

Specialty section:

This article was submitted to

Plant Abiotic Stress,

a section of the journal

Frontiers in Plant Science

Received: 17 May 2021

Accepted: 21 July 2021

Published: 13 August 2021

Citation:

Li S, Liu J, Liu H, Qiu R, Gao Y and Duan A (2021) Corrigendum: Role of Hydraulic Signal and ABA in Decrease

of Leaf Stomatal and Mesophyll

Conductance in Soil Drought-Stressed

Tomato. Front. Plant Sci. 12:710792.

doi: 10.3389/fp/s.2021.710792

\section{Corrigendum: Role of Hydraulic Signal and ABA in Decrease of Leaf Stomatal and Mesophyll Conductance in Soil Drought-Stressed Tomato}

\author{
Shuang Li ${ }^{1,2}$, Junming Liu ${ }^{1,2}$, Hao Liu ${ }^{1}$, Rangjian Qiu ${ }^{3}$, Yang Gao ${ }^{1 *}$ and Aiwang Duan ${ }^{1 *}$ \\ ${ }^{1}$ Key Laboratory of Crop Water Use and Regulation, Ministry of Agriculture and Rural Affairs, Farmland Irrigation Research \\ Institute, Chinese Academy of Agricultural Sciences, Xinxiang, China, ${ }^{2}$ Graduate School of Chinese Academy of Agricultural \\ Sciences, Beijing, China, ${ }^{3}$ School of Applied Meteorology, Nanjing University of Information Science and Technology, \\ Nanjing, China
}

Keywords: drought, leaf water potential, abscisic acid, stomatal conductance, mesophyll conductance, intrinsic water use efficiency

\section{A Corrigendum on}

Role of Hydraulic Signal and ABA in Decrease of Leaf Stomatal and Mesophyll Conductance in Soil Drought-Stressed Tomato

by Li, S., Liu, J., Liu, H., Qiu, R., Gao, Y., and Duan, A. (2021) Front. Plant Sci. 12:653186. doi: $10.3389 / f p l s .2021 .653186$

In the original article, there was an error in Figure 1 as published. The value of $\Psi_{\text {soil }}$ at 33 DAT should be -1.44 MPa. The corrected Figure 1 appears here.

The associated text in the Results section Dynamic of Soil Water Status has also been updated to reflect the correction to Figure 1, as described below.

The originally published sentence "By withholding irrigation from 27 to 33 DAT during the progressive drying process, RSWC in the drought treatment decreased gradually from 82.90 to $37.27 \%$ and $\Psi_{\text {soil }}$ decreased by $1.12 \mathrm{MPa}$ correspondingly." has been corrected to read "By withholding irrigation from 27 to 33 DAT during the progressive drying process, RSWC in the drought treatment decreased gradually from 82.90 to $37.27 \%$ and $\Psi_{\text {soil }}$ decreased by 1.04 MPa correspondingly."

In the original article, there was an error in Figure 3 as published. The value of $\Psi_{\text {soil }}$ at 33 DAT should be $-1.44 \mathrm{MPa}$. The corrected Figure 3 appears here.

The associated text in the Results section Quantitative Analysis of Photosynthetic Limitation in Response to Soil Drying has also been updated to reflect the correction to Figure 3, as described below. 


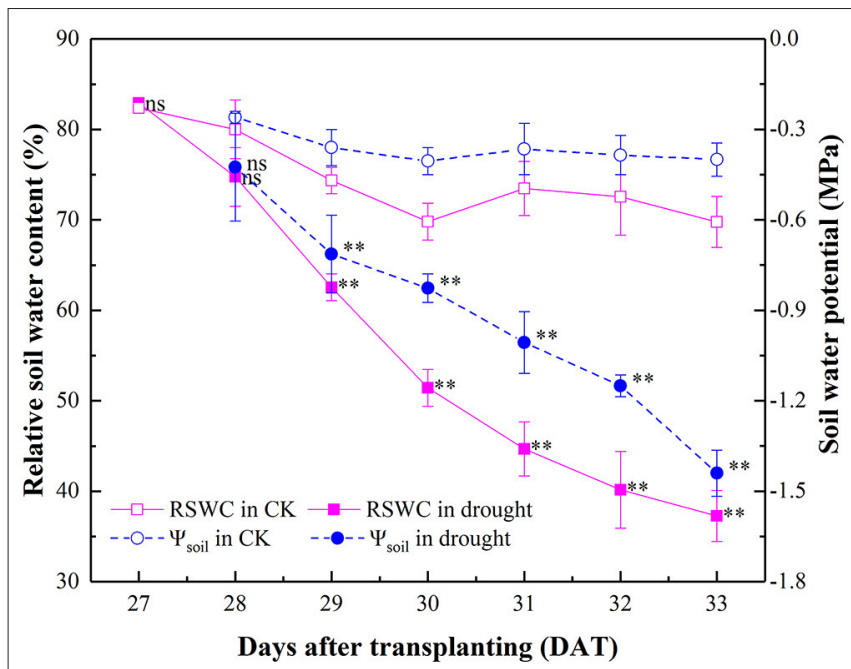

FIGURE 1 | Dynamics of RSWC and $\Psi_{\text {soil }}$ in the well-watered (CK) and drought-stressed tomato seedlings during 27-33 DAT. Mean values and SD were presented $(n=6)$. ns indicated no significant difference and ${ }^{\star *}$ indicated significant difference at $P<0.01$ level between drought and well-watered treatment.

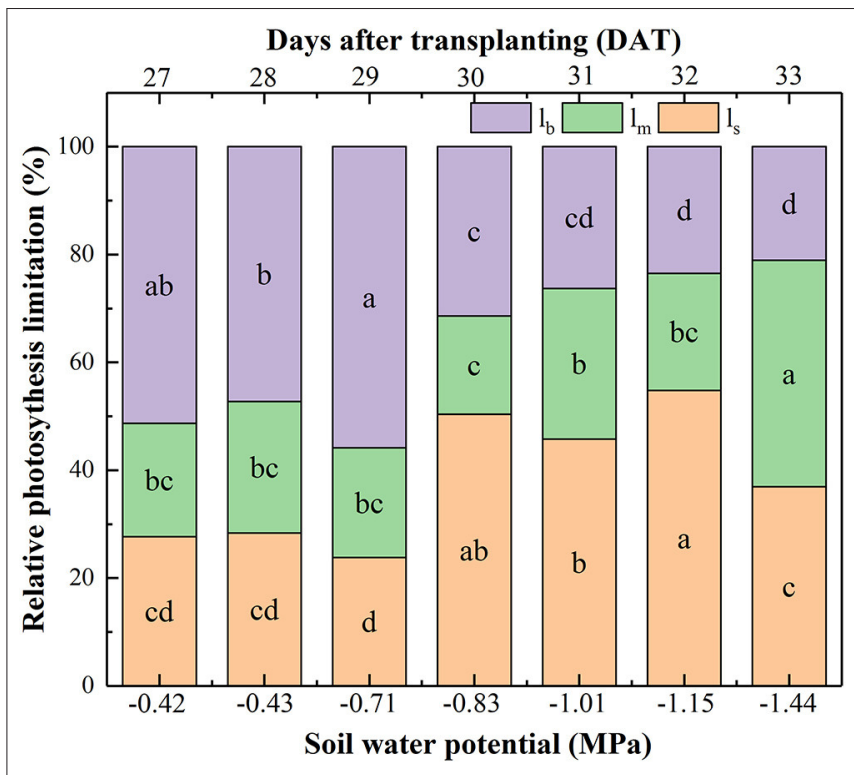

FIGURE 3 | Effect of soil water potential $\left(\Psi_{\text {soil }}\right)$ on the relative contribution of the photosynthesis capacity limiting factors: limitations of $A_{n}$ resulting from $g_{s}$ $\left(l_{s}\right), g_{m}\left(l_{m}\right)$, and biochemical photosynthetic capacity $\left(l_{b}\right)$ after transplanting. Data were means. Different letters indicated statistically significant difference between well-watered $(\mathrm{CK})$ and drought plants at $P<0.05$ level.

TABLE 2 | Sensitivity analyses of the effects of $\pm 20 \%$ error of light mitochondrial respiration $\left(\mathrm{R}_{\mathrm{d}}\right)$, chloroplast $\mathrm{CO}_{2}$ compensation point $\left(\Gamma^{\star}\right)$, electron transport rate $\left(J_{f}\right)$, and intercellular $\mathrm{CO}_{2}$ concentration $\left(\mathrm{C}_{\mathrm{i}}\right)$ on calculation of $\mathrm{g}_{\mathrm{m}}$ in well-watered and severe drought tomato at $\Psi_{\text {soil }}=-1.44 \mathrm{MPa}$ as compared with the original value of $\mathrm{g}_{\mathrm{m}}$.

\begin{tabular}{|c|c|c|c|c|c|}
\hline Factors & $g_{m}$ in CK & $g_{m}$ in drought & Factors & $g_{m}$ in $\mathrm{CK}$ & $g_{m}$ in drought \\
\hline$R_{d}-20 \%$ & $0.182 \pm 0.006 \mathrm{~ns}$ & $0.013 \pm 0.002 \mathrm{~ns}$ & $J_{f}-20 \%$ & $1.208 \pm 0.74^{\star \star}$ & $0.014 \pm 0.002 \mathrm{~ns}$ \\
\hline$R_{d}-10 \%$ & $0.189 \pm 0.005 \mathrm{~ns}$ & $0.013 \pm 0.002 \mathrm{~ns}$ & $J_{f}-10 \%$ & $0.309 \pm 0.020 \mathrm{~ns}$ & $0.014 \pm 0.002 \mathrm{~ns}$ \\
\hline$R_{d}+10 \%$ & $0.206 \pm 0.07 \mathrm{~ns}$ & $0.014 \pm 0.002 \mathrm{~ns}$ & $J_{f}+10 \%$ & $0.160 \pm 0.005 \mathrm{~ns}$ & $0.013 \pm 0.002 \mathrm{~ns}$ \\
\hline$R_{d}+20 \%$ & $0.216 \pm 0.08 \mathrm{~ns}$ & $0.014 \pm 0.002 \mathrm{~ns}$ & $J_{f}+20 \%$ & $0.141 \pm 0.004 \mathrm{~ns}$ & $0.013 \pm 0.002 \mathrm{~ns}$ \\
\hline$\Gamma^{\star}{ }^{\star}-20 \%$ & $0.146 \pm 0.005^{* *}$ & $0.013 \pm 0.002 \mathrm{~ns}$ & $C_{i}-20 \%$ & $0.433 \pm 0.025^{* \star}$ & $0.020 \pm 0.003$ * \\
\hline$\Gamma^{*}-10 \%$ & $0.168 \pm 0.009$ ** & $0.013 \pm 0.002 \mathrm{~ns}$ & $C_{i}-10 \%$ & $0.270 \pm 0.011^{* *}$ & $0.017 \pm 0.003 \mathrm{~ns}$ \\
\hline$\Gamma^{*}+10 \%$ & $0.238 \pm 0.015^{\star \star}$ & $0.014 \pm 0.002 \mathrm{~ns}$ & $C_{i}+10 \%$ & $0.155 \pm 0.005^{\star \star}$ & $0.013 \pm 0.002 \mathrm{~ns}$ \\
\hline$\Gamma^{*}+20 \%$ & $0.301 \pm 0.011^{\star \star}$ & $0.014 \pm 0.002 \mathrm{~ns}$ & $C_{i}+20 \%$ & $0.127 \pm 0.004^{* \star}$ & $0.011 \pm 0.002 \mathrm{~ns}$ \\
\hline
\end{tabular}

Data were mean $\pm S D(n=6)$. ns indicated no significant difference and ${ }^{\star *}$ indicated significant difference at $P<0.01$ level between drought and well-watered treatment.

The originally published sentence "Thirdly, with $\Psi_{\text {soil }}$ decreasing to $-1.54 \mathrm{MPa}, \mathrm{l}_{\mathrm{m}}$ contributed to $41.99 \%$ reduction in photosynthesis, followed by $l_{\mathrm{s}}(36.93 \%)$ and $l_{\mathrm{b}}(21.08 \%)$, showing that $\mathrm{g}_{\mathrm{m}}$ was the most important limiting factor to photosynthetic capacity under the severe drought condition." has been corrected to read "Thirdly, with $\Psi_{\text {soil }}$ decreasing to -1.44 $\mathrm{MPa}, \mathrm{l}_{\mathrm{m}}$ contributed to $41.99 \%$ reduction in photosynthesis, followed by $l_{s}(36.93 \%)$ and $l_{b}(21.08 \%)$, showing that $g_{m}$ was the most important limiting factor to photosynthetic capacity under the severe drought condition."

In the original article, there were errors in Table 2 as published. Owing to a miscalculation, the values of the parameters were incorrect. The corrected Table 2 appears here.

The associated text has also been updated to reflect to reflect the correction to Table 2, as described below.
In the Results section Sensitivity Analyses of Parameters in the Estimation $g_{m}$, the originally published sentence " $20 \%$ variation of $\mathrm{R}_{\mathrm{d}}, \Gamma^{*}$ did not affect $\mathrm{g}_{\mathrm{m}}$ significantly (Table 2)." has been corrected to read " $10 \%$ variation of $\mathrm{R}_{\mathrm{d}}$ and $\mathrm{J}_{\mathrm{f}}$ did not affect $\mathrm{g}_{\mathrm{m}}$ significantly, whereas $\Gamma^{*}$ has a significantly effect on $\mathrm{g}_{\mathrm{m}}$ in well-watered plants (Table 2)."

In the Results section Sensitivity Analyses of Parameters in the Estimation $g_{m}$, the originally published sentence " $20 \%$ underestimation of $C_{i}$ resulted in an overestimation of $g_{m}$, while $\mathrm{g}_{\mathrm{m}}$ was unaffected by overestimation of $\mathrm{C}_{\mathrm{i}}$ in both the wellwatered and drought treatments." has been corrected to read "Variation of $C_{i}$ resulted in an overestimation of $g_{m}$ in wellwatered plants, whereas $g_{m}$ in drought treatment was unaffected by overestimation of $\mathrm{C}_{\mathrm{i}}$."

In the Discussion section Response of $g_{m}$ to $\Psi_{\text {leaf }}$ and $A B A$ Under Soil Drought, the originally published sentence "However, 
the sensitivity analyses showed that an overestimation of $\mathrm{C}_{\mathrm{i}} \mathrm{did}$ not induce $\mathrm{g}_{\mathrm{m}}$ decline neither in the well-watered nor droughtstressed plants (Table 2)." has been corrected to read "However, the sensitivity analyses showed that an overestimation of $\mathrm{C}_{\mathrm{i}} \mathrm{did}$ not induce $g_{m}$ decline in drought-stressed plants (Table 2)."

In the original article, there were errors (incorrect $P$-values) in the following sentence from the Results section $\Psi_{\text {leaf }}$ and $A B A$ in the Regulation of $g_{s}, g_{m}, g_{t}$, and $A_{n}$ : "In summary, ABA was negatively related to $\mathrm{g}_{\mathrm{m}}(r=-0.64, P<0.001)$ and $g_{s}(r=-0.55, P<0.001)$ (Table 1)." The sentence should have read "In summary, ABA was negatively related to $\mathrm{g}_{\mathrm{m}}(r=-0.64, P<0.01)$ and $\mathrm{g}_{\mathrm{s}}(r=-0.55, P<0.01)$ (Table 1)."

The authors apologize for these errors and state that they do not change the scientific conclusions of the article in any way. The original article has been updated.

Publisher's Note: All claims expressed in this article are solely those of the authors and do not necessarily represent those of their affiliated organizations, or those of the publisher, the editors and the reviewers. Any product that may be evaluated in this article, or claim that may be made by its manufacturer, is not guaranteed or endorsed by the publisher.

Copyright (c) $2021 \mathrm{Li}, \mathrm{Liu}, \mathrm{Liu}, \mathrm{Qiu}, \mathrm{Gao}$ and Duan. This is an open-access article distributed under the terms of the Creative Commons Attribution License (CC BY). The use, distribution or reproduction in other forums is permitted, provided the original author(s) and the copyright owner(s) are credited and that the original publication in this journal is cited, in accordance with accepted academic practice. No use, distribution or reproduction is permitted which does not comply with these terms. 